\title{
Hidatidosis pulmonar
}

\author{
Dr. Juan Rodulfo', Dra. Mónica Carrión², Dra. Maribel Freitas³, \\ Dr. Javier Real ${ }^{4}$, Dra. Marisbell Merchán ${ }^{5}$ \\ 1 Hospital Universitario “Dr. Manuel Núñez Tovar” Maturín-Monagas. \\ 2 Complejo hospitalario Universitario Dr. Luis Razetti, Barcelona-Anzoátegui. \\ 3 Centro Clínico La Pirámide, Maturín-Monagas. \\ 4 Hospital Luis Ortega, Porlamar-Nueva Esparta. \\ 5 Clínica José María Vargas, Araure-Portuguesa.
}

\section{PULMONARY HYDATIDOSIS}

Pulmonary hydatidosis is a parasitic disease caused by Echinococcus granulosus in its larval form that parasitizes the intestine of the dog and infects humans as accidental intermediate host. Is related to socio-poor sanitary conditions. It has a worldwide distribution with peaks in Argentina, Uruguay and Chile and European countries like Greece, Portugal and Spain. In Venezuela is rare. In general, patients remain asymptomatic for a long time due to slow growth of cysts that can affect any organ of the anatomy, but are located in most cases in liver and lung. Most patients have a single cyst, that is more common in the lower lobe of the right lung. Chest radiography to visualize the cavitated lesions, specifying the location, number and sizes through the chest tomography or resonance. Immunoserological studies can confirm the diagnosis. Surgical treatment is preferred, but medical treatment is reserved for multiple cysts, only single vesicle les than $5 \mathrm{~cm}$, patients at high surgical risk or inoperable as pre and postoperative chemoprophylaxis. The drug of choice is albendazole. This condition is very rare in Venezuela, however radiologic imaging characteristics orient the diagnosis to confirm with immunoserologycs. In the case report draws attention to the bilateral nature of the condition is less common and good evolution with medical treatment in a short time.

Key words: Pulmonary hydatidosis, echinococcus.

\section{RESUMEN}

La hidatidosis pulmonar es una enfermedad parasitaria producida por el Echinococcus granulosus en su forma larvaria que parasita el intestino del perro e infecta al ser humano como huésped intermediario accidental. Está en relación con condiciones socio-sanitarias deficientes. Tiene una distribución mundial siendo más frecuente en Argentina, Uruguay y Chile y países europeos como Grecia, Portugal y España. En Venezuela es poco frecuente. En general los pacientes permanecen asintomáticos durante mucho tiempo, debido al crecimiento lento de los quistes que pueden afectar a cualquier órgano de la anatomía, aunque se localizan en la mayoría de los casos en hígado y pulmón. La mayoría de los enfermos presentan un solo quiste y es más frecuente en el lóbulo inferior del pulmón derecho. La radiografía de tórax permite visualizar la lesiones cavitadas, precisándose su ubicación, número y tamaños a través de la tomografía o resonancia de tórax. Los estudios inmunoserológicos permiten confirmar el diagnóstico. El tratamiento quirúrgico es de elección, sin embargo, el tratamiento médico está reservado para quistes múltiples, únicos univesiculares $<5 \mathrm{~cm}$, pacientes de alto riesgo quirúrgico o inoperables y como quimioprofilaxis pre y postoperatoria. El fármaco de elección es el albendazol. Esta patología es muy poco frecuente en Venezuela, sin embargo, las imágenes radiológicas características permiten orientar el diagnóstico para confirmarlo con los estudios inmunoserológicos. En el caso reportado llama la atención de la bilateralidad de la afección que es lo menos común y la buena evolución con tratamiento médico en corto tiempo.

Palabras clave: Hidatidosis pulmonar, echinococcus.

\section{INTRODUCCIÓN}

La hidatidosis es una zoonosis producida por quistes hidatídicos, larvas enquistadas del metacéstodo que pertenece al género Echinococcus que parasita el intestino del perro.

Correspondencia: Dr. Juan Rodulfo.

Hospital Universitario "Dr. Manuel Núñez Tovar" Maturín-Monagas.
Tiene una distribución mundial, conocida desde la época de Hipócrates; es decir es una enfermedad de los animales que eventualmente compromete al hombre. Predomina en zonas de cría de ganado ovino, bovino o caprino, y con menos frecuencia en donde existen otras poblaciones de animales herbívoros; relacionada con la ganadería en régimen extensivo o con infraestructuras sanitarias deficientes, asociadas generalmente a bajos niveles socioeconómicos y a la ausencia de educación sanitaria.

Alcanza una alta incidencia en países como Argentina, Uruguay, Chile, Australia, Nueva Zelanda y Europa, funda- 
mentalmente en Grecia, Portugal y España ${ }^{(I)}$. Es infrecuente en Venezuela. Existen algunos casos publicados, pero como esta enfermedad zoonótica es desconocida por los médicos, ha sido confundida con lesiones cancerosas inoperables. Luego, la biopsia hace el diagnóstico. Razetti en I90। fue el primero en mencionar el término de quiste hidatídico que había sido observado en Argentina. El primer caso venezolano de quiste hidatídico fue pulmonar, posiblemente debido a $E$. granulosus, en una paciente inmigrante de zonas endémicas de esa especie ${ }^{(2)}$. Recientemente en el año 201 I, fue reportado por los autores de este artículo un caso de hidatidosis pulmonar poliquística debido a Equinococus granulosus en un escolar de 8 años de edad en la ciudad de Maturín, estado Monagas; quien habitaba en área rodeada de perros callejeros, de este caso se hará mención en este artículo de revisión.

Se acepta dentro del género Echinococcus, cuatro especies: granulosus, multilocularis, vogeli y oligarthrus, siendo la primera la más frecuente ${ }^{(3)}$. La diseminación de esta patología ha sido favorecida por hábitos y conductas perniciosas que facilitan la infección de animales y del mismo hombre, como son la alimentación de los perros con vísceras crudas infectadas con quistes Hidatídicos obtenidas de matanzas familiares o clandestinas y el estrecho contacto que existe entre ambos ${ }^{(4)}$.

El Echinococcus granulosus en su forma adulta vive en el intestino del perro eliminando huevos periódicamente con la materia fecal. Estos huevos pueden ser ingeridos accidentalmente por los huéspedes intermediarios, entre ellos en hombre. En el intestino delgado los huevos eclosionan liberando el embrión hexacanto, quién pasa a través de las vellosidades intestinales a la circulación venosa hasta alojarse en el tejido hepático donde formará la hidátide. En caso de ser superado el filtro hepático el embrión continúa por el sistema circulatorio hasta el pulmón. Eventualmente puede continuar su migración alcanzando variadas localizaciones tal como riñón, cerebro, tejido óseo, muscular, etc ${ }^{(5)}$.

Los quistes característicos de la hidatidosis poseen diferentes localizaciones, pero 65\% se localiza en hígado y $10 \%$ en pulmón, siguiendo en orden decreciente en cerebro. Condiciona hemorragias, atrofias, necrosis por compresión vascular, hipertensión endocraneal, ictericia por compresión de vías biliares entre otros. La presencia de estas lesiones plantea problemas diagnósticos diferenciales con neoplasias y abscesos. El abordaje diagnóstico por laboratorio incluye métodos directos e indirectos. El interés para diagnosticar acertadamente esta parasitosis ha traído consigo el diseño y elaboración de técnicas de laboratorio rápidas, específicas y accesibles ${ }^{(6)}$

Aproximadamente el $75 \%$ de los quistes se localizan en el hígado, sobre todo en el lóbulo derecho, 30\% en el pulmón y alrededor de un 15\% en otros órganos. En 20\% de los casos se observan quistes en varias ubicaciones. El quiste contiene un líquido claro y transparente que lo mantiene distendido. En la pared se distinguen dos capas, la externa, formada por mucopolisacáridos, es acelular y de estructura laminada y la capa interna o membrana germinativa, que prolifera y origina agregados de células que se vacuolizan y forman las denominadas vesículas prolíferas. A su vez, por gemación, en el interior de ellas se forman escólex o cabezas de las futuras tenias. Con el tiempo, las vesículas se desprenden de la membrana germinativa y flotan libremente en el interior del quiste (vesículas hijas) algunas se rompen y liberan los escólex, que se acumulan en el fondo del quiste en forma de la denominada arena hidatídica. El quiste está envuelto por una cápsula de tejido conjuntivo o adventicia, que procede de la transformación fibrosa del órgano donde asienta. Crece lentamente, alrededor de I cm por año, comprimiendo las estructuras adyacentes ${ }^{(7)}$.

\section{CLÍNICA}

La evolución del quiste hidatídico puede ser silenciosa por varios años. Durante la etapa de crecimiento silente o preclínico, su presencia pasa inadvertido por el paciente y por el médico, luego se exterioriza por síntomas y signos inherentes al órgano donde se aloja ${ }^{(8)}$. En el hígado se manifiesta por dolor o por una sensación vaga de plenitud en hipocondrio derecho, pudiéndose hallar a la exploración física hepatomegalia uniforme si el quiste crece en el centro del hígado, o de aspecto tumoral si lo hace en la superficie ${ }^{(9)}$.

En el pulmón el quiste no complicado presenta síntomas discretos como: dolor vago, tos, expectoración o disnea ${ }^{(3)}$ y al examen físico signos de tumoración como matidez, disminución del ruido respiratorio y soplo(10). Puede presentar sintomatología de insuficiencia respiratoria ${ }^{(8)}$. En la mayoría de los casos, los síntomas comienzan cuando el quiste tiene 5 a $6 \mathrm{~cm}$ de diámetro. Los quistes pulmonares se suelen descubrir durante una exploración radiológica del tórax efectuada por otras razones ${ }^{(1)}$. La mayoría de los enfermos presentan un solo quiste y es más frecuente en el lóbulo inferior del pulmón derecho. La hidatidosis pulmonar múltiple puede ser primitiva o secundaria(3). En el primer caso, lo es frecuentemente por vía venosa, y la secundaria por contaminación local o embolígena proveniente de otras localizaciones a distancia ${ }^{(8)}$.

\section{COMPLICACIONES}

Si el quiste se rompe a los bronquios se produce hidatidoptisis o eliminación con la tos o por vómica de elementos hidatídicos macro o microscópicos (líquido sabor salado, restos de membranas, vesículas y elementos de la arenilla hidatídica). La vómica puede ser fraccionada, inaparente y puede acompañarse de hemoptisis. Si el quiste es evacuado a los bronquios en forma parcial, como sucede frecuentemente, se produce hidroneumoquiste y luego una pioneumoquiste hidatídica, en un $5 \%$ de los casos al quedar retenido en la cavidad elementos hidatídicos, se produce lo que se llama "membranas incarceladas".

Los quistes hidatídicos que crecen hacia la superficie pulmonar pueden romperse a la cavidad pleural originando una reacción serosa y rara vez una hidatidosis pulmonar secundaria ${ }^{(3)}$. El líquido hidatídico constituye el principal responsable de la estimulación antigénica ${ }^{(5)}$. El enfermo puede sensibilizarse frente a las proteínas del quiste cuando su contenido escapa hacia los tejidos. El 20\% de los pacientes presenta reacciones anafilácticas, brotes recurrentes de urticaria 
generalizada, aumento de los niveles de lg E y/o eosinofilia. El shock anafiláctico como manifestación de la enfermedad es infrecuente, oscilando entre cifras que van desde el I al $7,5 \%$ (2). El diagnóstico etiológico es fácil cuando el shock se presenta durante la manipulación quirúrgica del quiste hidatídico, pero la dificultad surge cuando se produce por la rotura espontánea del mismo(9).

\section{DIAGNÓSTICO}

En las zonas endémicas las características clínicas hacen sospechar la presencia de la enfermedad; este diagnóstico clínico raramente se hace en regiones en las cuales la hidatidosis no es frecuente ${ }^{(I)}$.

Actualmente, el diagnóstico de la hidatidosis humana está basado en la combinación de métodos de tratamiento de imagen (ecografía, tomografía computarizada, resonancia magnética, rayos $X$ ) y ensayos inmunodiagnósticos (principalmente análisis inmunoenzimático [ELISA] e immunoblotting), estos últimos habitualmente utilizados como técnicas de confirmación de los casos sospechosos ${ }^{(12)}$. En el hemograma, el hallazgo más frecuente es la eosinofilia de más de 5\%, signo que es compartido por otras patologías de tipo parasitarios como la ascariasis, triquinosis, larva migrans y la cisticercosis. Puede encontrarse también leucocitosis cuando el quiste presenta alguna complicación de tipo infeccioso. Perfil hepático (hepatograma): La elevación de las transaminasas y/o hiperbilirrubinemia sugieren complicaciones del quiste o compromiso de la vía biliar (rotura, abscedación) ${ }^{(13)}$.

\section{DIAGNÓSTICO POR IMÁGENES}

\section{Radiografía de tórax}

Tiene un excelente rendimiento ya que permite el diagnóstico de las lesiones pulmonares y sospechar la presencia de quistes hepáticos cuando hay elevación diafragmática. Se pueden observar signos característicos cuando el quiste se comunica con la vía aérea. El aire sirve de contraste para el contenido líquido de la hidátide, y los signos son el neumope- riquiste, cuando el aire se ubica por dentro de la periquística y la separa del endoquiste; el signo del camalote cuando el quiste se ha vaciado parcialmente y es posible observar la membranas flotando en el líquido hidatídico restante; y el morchio o imagen poligonal cuando el quiste se ha vaciado completamente y sólo quedan las membranas ${ }^{(13)}$ (Figura I). Pudiéndose clasificar de acuerdo a las imágenes radiológicas según Polat et al (Tabla I).

La TAC y la RMN complementa los hallazgos de la radiografía simple y es de gran valor para identificar el componente líquido del quiste. También es útil para precisar las características de la pared del quiste es identificar lesiones asociadas, lo cual permite seleccionar más adecuadamente el proceso

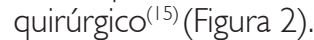

La ecografía muestra de manera característica quistes avasculares con estructuras internas compatibles con quistes hijos. La detección de calcificación mural apoya firmemente el diagnóstico de quiste hidatídico. Desde el punto de vista qui-

Tabla I. Clasificación de Polat et al en base a la apariencia radiológica ${ }^{(14)}$

\begin{tabular}{|c|c|c|}
\hline Tipo & Subtipos & Características radiológicas \\
\hline I & & Quiste simple sin "arquitectura interna" \\
\hline \multirow[t]{3}{*}{$\|$} & $\| A$ & $\begin{array}{l}\text { Vesículas hijas redondeadas en la periferia de } \\
\text { quiste (vesículas de menor atenuación que } \\
\text { quiste) }\end{array}$ \\
\hline & $\| B$ & $\begin{array}{l}\text { Vesículas hijas de mayor tamaño y morfología } \\
\text { más irregular que ocupan la práctica toralidad } \\
\text { del quiste. Imagen en roseta }\end{array}$ \\
\hline & $\| \mathrm{C}$ & $\begin{array}{l}\text { Masas de densidad relativamente alta con calci- } \\
\text { ficaciones dispersas y alguna vesícula ocasional. } \\
\text { representan la degeneración de un quiste viejo. }\end{array}$ \\
\hline III & & $\begin{array}{l}\text { Quistes "muertos" con calcificación total de } \\
\text { mismo }\end{array}$ \\
\hline IV & & $\begin{array}{l}\text { Quiste complicado por rotura o sobreinfección } \\
\text { de un quiste tipo I o I| }\end{array}$ \\
\hline
\end{tabular}
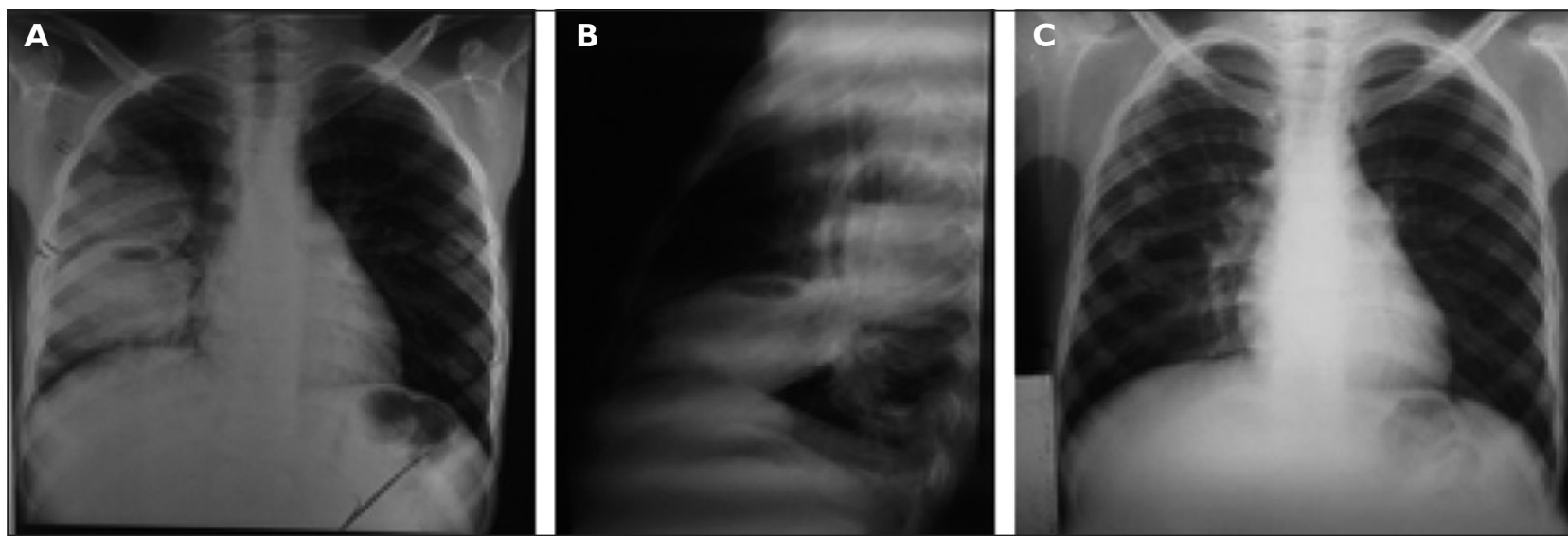

Figura I. Escolar de 9 años con tos húmeda, disnea y dolor torácico de 2 sem de evolución, con diagnóstico de hidatidosis pulmonar por Echinococcus granulosus. A) Rx P-A de tórax: Lesiones cavitadas bilaterales a predominio de campo pulmonar derecho; B) Rx lateral de tórax: se evidencian las lesiones cavitadas con niveles hidroaéreos; C) Rx P-A de tórax: imágenes en clara resolución 2 I días posterior a estar recibiendo Albendazol. 

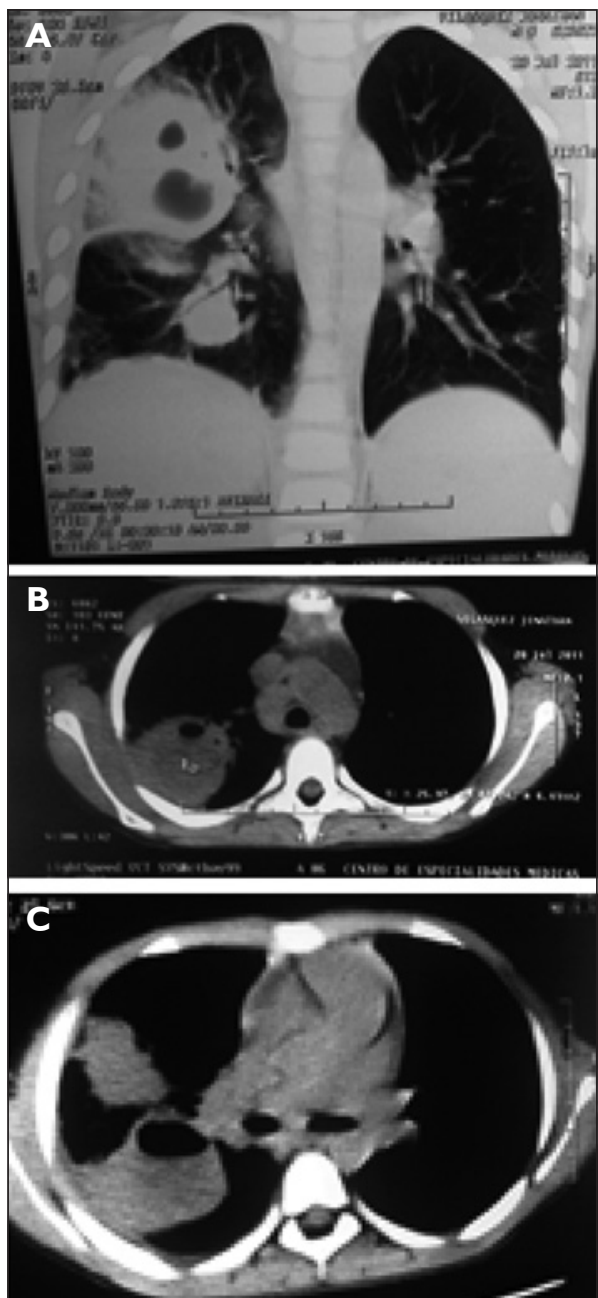

Figura 2. TAC de tórax de escolar de 9 años de edad de hidatidosis pulmonar. Apreciándose imágenes cavitadas con nivel hidroaéreo a nivel del pulmón derecho.

rúrgico, la ecografía permite seleccionar al cirujano la vía de abordaje de acuerdo con la localización del quiste, y le brinda además referencias anatómicas de la lesión con las estructuras intrahepáticas; esto es de utilidad en la cirugía de resección ${ }^{(16)}$.

Diagnóstico diferencial: cuando el quiste se halla en pulmón debe diferenciarse entre el carcinoma pulmonar primario o metastático, el absceso pulmonar y la tuberculosis. En un segundo plano queda la sospecha de infecciones por hongos, nocardias y otros procesos menos frecuentes ${ }^{(17)}$. Cuando se localiza en hígado, debe diferenciarse entre hemangioma, carcinoma metastático y absceso hepático bacteriano o amebiano(15).

\section{DIAGNÓSTICOS DE LABORATORIO}

a) Inmunoelectroforesis: se basa en una banda de precipitación en la zona de las albúminas conocido como Arco 5, descrito por Caprón. Su presencia confirma la enfermedad, pero su ausencia no la descarta. Su sensibilidad es de 94\%. b) Prueba de aglutinación: es útil para diagnósticos serológicos, es muy sencilla de realizar y está al alcance de cualquier operador. Su sensibilidad es de 64\%.

c) Hemaglutinación indirecta cuantitativa: es útil para complementar las pruebas anteriores por su grado de especificidad. Se considera positiva a títulos de 1/320 o más. La sensibilidad es del 94\%.

d) La doble difusión Arco 5 (DD5): se la puede realizar en laboratorios de bajos recursos. Tiene una sensibilidad semejante a la inmunoelectroforesis.

e) ELISA: para detección de portadores no sintomáticos. Útil en pacientes operados y/o en tratamiento con Albendazol, la primer determinación debe realizarse antes de la cirugía o de iniciarse el tratamiento. Es sensible en un 50-56\% para los quistes pulmonares.

f) Intradermoreacción de Casoni: existen opiniones divergentes sobre su valor.

g) Anticuerpos monoclonales.

h) Exámenes parasitológicos de líquidos orgánicos: en casos de quistes comunicados con el exterior. El examen microscópico de material obtenido por eliminación espontánea o a través de fístulas, rupturas a bronquios, etc., demuestra los embriones característicos ${ }^{(9)}$.

\section{TRATAMIENTO}

El tratamiento de la hidatidosis pulmonar es quirúrgico y consiste en la erradicación de los quistes, la corrección de los efectos de la presencia del quiste en el órgano (periquística y cavidad residual) y tratar la complicaciones que el quiste a provocado en su evolución (fístulas bronquiales y siembra pleural). El tratamiento médico está reservado para quistes múltiples, únicos univesiculares $<5 \mathrm{~cm}$, pacientes de alto riesgo quirúrgico o inoperables y como quimioprofilaxis pre y postoperatoria. Los fármacos utilizados son los derivados benzoimidazólicos y de ellos, el de elección es el albendazol por tener mejor absorción, este impide la utilización de la glucosa por parte del parásito y la duración del tratamiento se recomiendan 3 a 6 ciclos de 4 a 6 sem y como quimioprofilaxis 4 a 7 días antes de la cirugía y I a 3 ciclos en el postoperatorio.

Las contraindicaciones del tratamiento quirúrgico: se dan en los casos de quistes múltiples, quistes no viables, quistes de difícil abordaje o localización no accesible, los quistes que estén parcial o totalmente calcificados y los quistes de muy pequeño tamaño. La estrategia de prevención consiste en romper el ciclo biológico del parásito, con particular énfasis en las zonas endémicas, lo que se logra desparasitando a los perros y realizando practica de medidas higiénicas básicas: agua potable, lavado correcto de verduras y evitar alimentar a los perros con las vísceras de animales faenados ${ }^{(18,19)}$.

\section{CONCLUSIONES}

La hidatidosis pulmonar es una es una zoonosis de distribución mundial, con alta incidencia en países latinoamericanos como: Argentina, Uruguay y Chile y europeos como Grecia, Portugal y España, relacionados con deficientes condiciones 
socio-económicas y malos hábitos higiénicos, en países como Venezuela es infrecuente o por lo menos hay muy pocos casos reportados, lo que hace que para su sospecha diagnostica, además del antecedente epidemiológico de contactos con caninos, se deba enfocar en el aspecto radiológicos en el que la Rx Postero Anterior y lateral de tórax, permiten evideciar imágenes características que pueden hacer pensar en el mismo y plantear, otros estudios imagenologicos como la TAC o la RMN, asi como el diagnóstico serológico y a su vez iniciar tratamiento con derivados benzoimidazólicos, en el que el albendazol es uno de los medicamentos en el que se tiene mayor experiencia y que ha permitido mejorar la evolución, el riesgo de recidiva; asi como evitar en algunos casos con excelente respuesta, el tratamiento quirúrgico que en casos específicos es el de elección. En el caso reportado en este artículo de revisión el paciente presento una excelente respuesta a pesar del compromiso pulmonar y en 21 días de tratamiento una casi total resolución radiológica.

\section{REFERENCIAS}

I. Sánchez Acedo C, Estrada Peña A, Del Cacho Malo E, et al. ¿Qué es la Hidatidosis?. Departamento de Patología animal. Facultad de Veterinaria. Universidad de Zaragoza. España. Unizar [en línea] 1997 [fecha de acceso 22 de septiembre de 2005]; URL. Disponibleen: http://wzar.unizar.es/hidatidosis/hid/hid info.html.

2. Gómez L, Luna G. Primeros casos de quiste hidatídico del pulmón encontrados en Venezuela. Memorias del I Congreso Venezolano de la Tuberculosis Caracas-Venezuela 1938; 573-6.

3. Sapunar J. Hidatidosis. En Atías A, de: Parasitología médica. Chile: Publicaciones Técnicas Mediterráneas 338-54.

4. Ribal M, Lidid L, López B, Apt W, Zulantay I, De Diego P. Hidatidosis múltiple. Rev. Parasitología al día. [En línea] 2000 [fecha de acceso 18 de febrero de 2007] 24: 46-8. Disponible en: http://www.scielo.cl/scielo.php?pid=S07 | 6-07202 000000 l $00007 \&$ script $=$ sci arttext

5. Larrieu E, Del Carpio M, Gatti A, et al. Normas de diagnóstico y tratamiento de la Hidatidosis humana. Secretaria de estado de salud. Provincia de Río Negro. [en línea] 2002 [fecha de acceso 16 de septiembre de 2005]; Disponible en: http://www. saludambiental.gov.ar/HIDATIDOSIS/normas\%20medicas.htm
6. Sánchez-González J, Rivera Cisneros AE, Vázquez MA, Cruz Luna A, Farfán MR, Andrade Quezada M. Anticuerpos Anti- Echinococcus (Hidatidosis) mediante hemaglutinación pasiva, en sujetos expuestos a riesgos. Rev Mex Patolog Clínica 1997; 44: 233-9.

7. Pérez A, Costa NT, Cantón G, et al. Vigilancia epidemiológica del la equinococosis quística en perros, establecimientos ganaderos y poblaciones humanas en la provincia de Río Negro. Revista Medicina Buenos Aires 2006; 166: 193-200.

8. Gorodner J. Hidatidosis. En: Gorodner JO, Gorodner AM, de Enfermedades infecciosas. 2da Edición. Rosario. Argentina: Editorial Corpus, 2004: 102-11.

9. Cerrada Cerrada E, López Olmeda C, Gómez Rodríguez BM, Eixarch Alias A. Anafilaxia y quiste hidatídico. MEDIFAM [en línea] Junio de 2002 [fecha de acceso septiembre de 2005]; URL disponible en: http://scielo.isciii.es/pdf/medif/v|2n6/notacli I .pdf.

10. Botero DR, Restrepo MI, Helmintiasis tisulares. En: Restrepo AM, Robledo J, Bedoya VIE, de: Enfermedades infecciosas. $5^{\circ}$ Edición. Medellín, Colombia. Corporación para investigaciones biológicas. 1996: 507-20.

I I. Berkow R. El Manual Merk, $10^{\circ}$ edición. Madrid. España: Editorial Harcout, 1999: 1282-3.

12. Eckert J, Deplazes P. Biological, epidemiological, and clinical aspects of echinococcosis, a zoonosis of increasing concern. Clin Microbiol Rev 2004; 17: 107-35.

13. Vera GM, Venturelli FM, Ramírez JT, Venturelli AL. Hidatidosis humana. Revista Cuadernos de cirugía 2003; 17: 88-94.

14. Polat P, Kantarci M, Alper F, et al. Hydatid Disease from Head to Toe. Radiographics 2003; 23; 475-94.

I5. Leto RC, Ponce M, Ojeda M, Ramos Cosimi JJ. Aspectos clínicos y terapéuticos de la enfermedad hidatídica. Revista de posgrado de la VI cátedra de medicina 2006; I 59: 12-6.

16. Andreani OC. Hígado. En: Ferraina P, Oria A. Cirugía de Michans. $5^{\circ}$ ed. Buenos Aires Argentina: Editorial El Ateneo. 1999: 477-555.

17. Franco MA, Gallardo M, Conde A, Cruz JM, Contreras M. Masa pulmonar que se cavita tras broncoscopía. Rev Enf Infec Microb Clin 1998; 16: 287-8.

18. Muñoz P. Diagnóstico y tratamiento de la Hidatidosis (comentario editorial). Rev Chil Infectol 2007; 24: I 53-4.

19. Cortés S, Valle C. Hidatidosis Pulmonar: Generalidades y situación epidemiológica en Chile según egresos hospitalarios y notificación obligatoria entre los años 2001 y 2005. Rev Chil Infect 20 I0; 27: 329-35. 